\title{
ENSAYOS PRELIMINARES PARA PRODUCCIÓN DE CELULOSA POR BACTERIAS AISLADAS DE CAÑA DE AZÚCAR
}

\author{
Jonathan Tuya Salas*, Susana Gutiérrez Moreno ${ }^{a}$, Fernando Merino Rafael ${ }^{\mathrm{a}}$
}

\begin{abstract}
RESUMEN
La celulosa bacteriana tiene una variedad de aplicaciones tanto en las industrias del papel, textil, alimentaria, cosmética y la medicina; esto se debe a sus excelentes propiedades fisicoquímicas tales como: alto grado de pureza, alta cristalinidad, excelente biodegradabilidad, un alto módulo de Young, una gran capacidad de retención de agua y una excelente afinidad biológica. Este trabajo tuvo como objetivo evaluar la producción de celulosa por bacterias aisladas de caña de azúcar. Las muestras recolectadas se dejaron fermentar hasta la aparición de una película gruesa en la superficie, a partir de la cual se obtuvieron cultivos axénicos sobre el medio HS. Los cultivos aislados se transfirieron a caldo HS y se incubaron en condiciones estáticas hasta la formación de una película en la superficie del cultivo. La identificación bacteriana se realizó en base a una caracterización fisiológica de las cepas aisladas y su capacidad de producir celulosa. El análisis de FT-IR de la película mostró un espectro correspondiente a los grupos funcionales característicos de la celulosa bacteriana y vegetal. La cepa BCP-3,5 identificada como Komagataeibacter sp. fue capaz de producir celulosa bacteriana en condiciones estáticas de cultivo.
\end{abstract}

Palabras clave: Celulosa, azúcar de caña, bacteria, biopolímero, Komagataeibacter sp.

\section{PRELIMINARY TEST FOR CELLULOSE PRODUCTION BY BACTERIA ISOLATED FROM SUGARCANE}

\begin{abstract}
Bacterial cellulose has a variety of applications both in the paper, textile, food, cosmetic and medicine industries; This is due to its excellent physicochemical properties such as: high degree of purity, high crystallinity, excellent biodegradability, high Young's modulus, high water retention capacity and excellent biological affinity. The objective of this work was to evaluate cellulose production by bacteria isolated from sugarcane. The collected samples were allowed to ferment until the appearance of a thick film on the surface, from which axenic

\footnotetext{
${ }^{* 1}$ Laboratorio de Microbiología y Biotecnología Microbiana, Facultad de Ciencias Biológicas, Universidad Nacional Mayor de San Marcos, Ciudad Universitaria, Av. Venezuela Cdra. 34 s/n Lima - Perú. email: jondavtusa@gmail.com
} 
cultures were obtained on the HS medium. Isolated cultures were transferred to HS broth and incubated under static conditions until a film formed on the culture surface. Bacterial identification was carried out based on a physiological characterization of the isolated strains and their capacity to produce cellulose. FT-IR analysis of the film showed a spectrum corresponding to the characteristic functional groups of bacterial and plant cellulose. The BCP-3,5 strain identified as Komagataeibacter sp. was able to produce bacterial cellulose under static culture conditions.

Key words: Cellulose, sugarcane, bacteria, biopolymer, Komagataeibacter sp.

\section{INTRODUCCIÓN}

La celulosa es uno de los biopolímeros más abundantes sobre la Tierra, es producido principalmente por las plantas como componente principal de su pared celular ${ }^{1}$. La celulosa es una materia prima que tiene múltiples propósitos: es material de construcción, generación de fibras textiles y fabricación de papel, además, sus derivados (ésteres, acetatos, nitratos) están implicados en diversos procesos industriales. Sin embargo, hay algunas especies de bacterias, como las de los géneros Achromobacter, Alcaligenes, Aerobacter, Agrobacterium, Azotobacter, Komagataeibacter, Pseudomonas, Rhizobium, Sarcina, Dickeya y Rhodobacter, que también pueden producir celulosa de forma extracelular ${ }^{2}$. La fórmula molecular de la celulosa bacteriana es la misma que la de la celulosa vegetal, pero sus características físicas y químicas son diferentes ${ }^{3}$. Él principal género microbiano productor y modelo de síntesis de celulosa es Komagataeibacter (antes Gluconacetobacter), perteneciente a la familia Acetobacteraceae, que son bacilos Gram negativos, aerobios obligados. Estas bacterias pueden aislarse de la superficie de muchas flores y frutos, entre ellos la caña de azúcar, además de bebidas fermentadas ${ }^{4,5,6}$. La producción de celulosa por Komagataeibacter, responde a necesidades fisiológicas. Las bacterias se adhieren al biopolímero para aumentar su exposición al oxígeno y para tomar los nutrientes contenidos en los líquidos absorbidos del ambiente, además los protege contra la radiación ultravioleta. En cultivos estáticos, la formación de celulosa se observa como una película en la interfase aire-líquido. En cultivos agitados la celulosa se agrupa en gránulos irregulares, también se observa la aparición espontánea de mutantes no productores de celulosa, esto crea inconvenientes para la producción en masa de este biopolímero ${ }^{7,8,9}$. La celulosa presenta características únicas: i) alto grado de pureza, ya que no contiene hemicelulosa ni lignina como si ocurre en la celulosa de origen vegetal; ii) alta cristalinidad; iii) excelente biodegradabilidad; iv) un alto módulo de Young (15 30 GPa), uno de los más alto de todos los materiales orgánicos; v) una gran capacidad de retención de agua, hasta cien veces su peso y vi) una excelente afinidad biológica ${ }^{10,11}$. Debido a las propiedades únicas, la celulosa ha encontrado una variedad de aplicaciones tanto en las industrias del papel, textil, alimentaria y como un biomaterial muy útil en la industria cosmética y la medicina ${ }^{11,12}$. Este trabajo tuvo como objetivo aislar bacterias de caña de azúcar capaces de producir de celulosa en condiciones de laboratorio. 


\section{PARTE EXPERIMENTAL}

\section{Recolección de muestras y procesamiento}

Un total de 5 muestras de cañas de azúcar fueron colectadas del mercado mayorista $\mathrm{N}^{0} 1$. Cada una de las muestras fueron lavadas superficialmente con agua destilada estéril, se tomaron aproximadamente $20 \mathrm{~mL}$ del agua de lavado y se depositaron en una botella de 500 $\mathrm{ml}$ conteniendo $300 \mathrm{~mL}$ de su propio extracto de caña. Las botellas fueron cubiertas con una gasa estéril y se dejaron incubar a temperatura ambiente por 25 días hasta la formación de una película en la superficie del extracto de caña.

\section{Condiciones de crecimiento y aislamiento}

En condiciones estériles, se tomó con el asa de siembra una alícuota de la superficie de la película y se sembró por agotamiento sobre el medio Hestrin-Schramm (HS) ${ }^{13}$. El medio contenía: 20,0 g/L de glucosa; 5,0 g/L de extracto de levadura; 5,0 g/L de peptona; $2,7 \mathrm{~g} / \mathrm{L}$ de $\mathrm{Na}_{2} \mathrm{HPO}_{4} ; 5,7 \mathrm{~g} / \mathrm{L}$ de $\mathrm{MgSO}_{4} .7 \mathrm{H}_{2} \mathrm{O} ; 1,15 \mathrm{~g} / \mathrm{L}$ de ácido cítrico; $\mathrm{pH}$ final de 5,7. El medio se autoclavó a $121{ }^{\circ} \mathrm{C}$ por $15 \mathrm{~min}$. Las colonias, seleccionadas preliminarmente, fueron catalogadas y transferidas a un nuevo caldo $\mathrm{HS}$ e incubadas por 2 días a $30^{\circ} \mathrm{C}$. Se aislaron colonias microbianas a partir de cada cultivo que presentó la formación de una película superficial. Este procedimiento se repitió hasta la obtención de cultivos puros. Finalmente se transfirió $0,1 \mathrm{ml}$ de un cultivo puro (incubado por 2 días a $30^{\circ} \mathrm{C}$ ) sobre $200 \mathrm{ml}$ de caldo $\mathrm{HS}$ y se incubo por 6 días a $30^{\circ} \mathrm{C}$, hasta la formación de una película superficial gruesa.

\section{Recuperación y caracterización de la película por FT-IR}

La película fue retirada del cultivo y lavada con agua del grifo, $200 \mathrm{ml}$ de $\mathrm{NaOH}$ al $2 \%$ (w/v) a $80{ }^{\circ} \mathrm{C}$ por $20 \mathrm{~min}$ y $200 \mathrm{ml}$ de ácido acético al $2 \%(\mathrm{v} / \mathrm{v})$, este tratamiento se repitió tres veces; finalmente, la película fue lavada con agua destilada estéril. Luego de ese tratamiento, la película fue secada a $80^{\circ} \mathrm{C}$ en una estufa durante 2 horas ${ }^{14,15}$. La caracterización química de la película se realizó mediante espectroscopia infrarroja, FT-IR (Modelo IMPACT 410, NICOLET), a una longitud de onda entre el rango de 4000 a $400 \mathrm{~cm}^{-1}$.

\section{Identificación de las cepas aisladas}

Se realizó siguiendo la metodología propuesta por Kersters et al. ${ }^{16}$ y Komagata et al. ${ }^{17}$. La identificación consistió en la realización de las siguientes pruebas: coloración Gram, catalasa, oxidación de etanol a ácido acético, oxidación de ácido acético a $\mathrm{CO} 2$ y H2O, oxidación de lactato a $\mathrm{CO}_{2} \mathrm{y} \mathrm{H}_{2} \mathrm{O}$, crecimiento sobre $3 \%$ etanol (v/v) en presencia de $5 \%$ de ácido acético, requerimiento de ácido acético para crecer, crecimiento en presencia de $30 \%$ de D-glucosa, formación de ácido glucónico y la producción de celulosa.

\section{RESULTADOS Y DISCUSIÓN}

Se lograron aislar, inicialmente, 7 cepas a partir de las muestras de caña de azúcar, de las cuales solo la cepa catalogada como CBP-3,5 mostró mayor producción de una película en la superficie del medio de cultivo HS después de los dos días de incubación. De acuerdo a otros 
estudios, la formación de celulosa en cultivos estáticos comienza generalmente después de 2 días de incubación; sin embargo, esto puede variar dependiendo de la cepa y las condiciones de cultivo ${ }^{3,18}$. Las colonias aisladas mostraron las siguientes características morfológicas: colonias cremas-blancas, secas, lisas, convexas, con un diámetro de entre 2 a $3 \mathrm{~mm}$ (figura 1A). Estas características morfológicas de las colonias sobre el medio HS fueron también reportadas en otras investigaciones ${ }^{3,19,20}$. La formación de una película superficial gruesa se observó luego del sexto día de incubación (figura 1B).
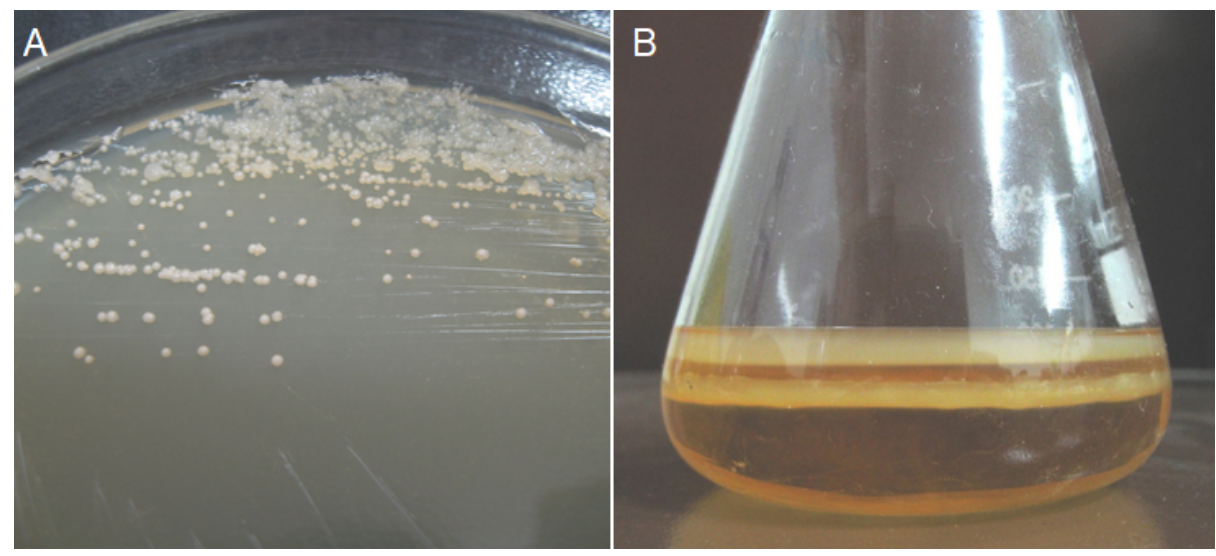

Figura 1. A: Colonias aisladas de caña de azúcar pertenecientes a la cepa CBP-3,5.

B: Formación de una película superficial producida por la cepa CBP-3,5 en cultivo estático sobre el medio HS durante 6 días de incubación a $30^{\circ} \mathrm{C}$.

Luego de recuperar la película del cultivo estático (figura 2A), se realizó un lavado con agua de la película y un tratamiento con $\mathrm{NaOH}$ al $2 \%$ a $80{ }^{\circ} \mathrm{C}$. Este tratamiento es útil para eliminar las células bacterianas adheridas a la película y restos del medio de cultivo empleado $^{14,21}$, sin llegar a hidrolizar la celulosa ni formar celulosa alcalina; además, mejora la porosidad y la elasticidad de la celulosa ${ }^{22,23}$. La celulosa bacteriana es estable en soluciones básicas, pero es susceptible a hidrólisis alcalina en condiciones drásticas. Concentraciones elevadas de álcali y temperaturas iguales o superiores a $100{ }^{\circ} \mathrm{C}$ pueden provocar la hidrólisis de la celulosa o formar celulosa alcalina, forma modificada de la celulosa ${ }^{24,25}$. Por otro lado, el tratamiento con ácido acético al $2 \%$ permite neutralizar el efecto del tratamiento con el álcali ${ }^{15}$. Luego del tratamiento con el $\mathrm{NaOH}$ y el ácido acético la película se vuelve traslúcida y pierde volumen debido al tratamiento de secado en horno (figura 2B). El tratamiento con calor permite secar la película para realizar el análisis por FT-IR sin afectar su cristalinidad. Aunque la celulosa bacteriana puede calentarse hasta $325^{\circ} \mathrm{C}$ antes de comenzar a quemarse ${ }^{11}$, se ha encontrado que a temperaturas de secado cercanas a los $50{ }^{\circ} \mathrm{C}$ puede llegar a afectar algunas de sus propiedades y sus posibles aplicaciones ${ }^{20}$. También se han reportado que estas temperaturas pueden producir polimorfismos de la celulosa, lo que fue se evidencia cuando se analizan los picos de absorción en los resultados de FT-IR ${ }^{26}$. 


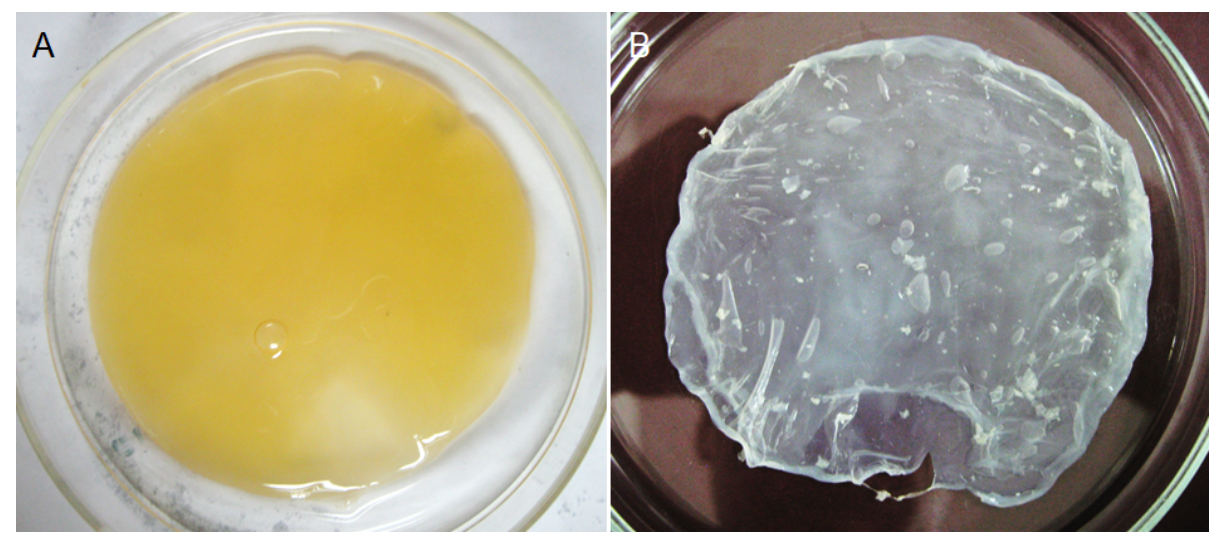

Figura 2. Película producida en cultivo estático por la cepa CBP-3,5. A: Antes del tratamiento con $\mathrm{NaOH}$ y ácido acético. B: Después del tratamiento y secado.

El análisis de FT-IR se utilizó para determinar los picos de absorción correspondientes a las vibraciones de enlaces en los grupos funcionales encontrados en la película ${ }^{11}$.

En la figura 3 se observa un pico a $3349,09 \mathrm{~cm}^{-1}$ correspondiente a las vibraciones de tensión del grupo $\mathrm{OH}$, vibraciones de tensión de los grupos $\mathrm{CH}$ y $\mathrm{CH} 2$ a 2918,27 $\mathrm{cm}^{-1}$, vibraciones de flexión del grupo $\mathrm{OH}$ a 1638,44 cm-1 debido a la retención de agua por la muestra, vibraciones de tensión del grupo COO a 1560,40 $\mathrm{cm}^{-1}$, vibraciones de tensión simétricas de los grupos $\mathrm{CH} 2$ o en el grupo $\mathrm{OH}$ a $1421,19 \mathrm{~cm}^{-1}$, vibraciones de flexión simétricas del grupo OH a 1204,43 $\mathrm{cm}^{-1}$, vibraciones de tensión del grupo C-O-C a 1159,28 $\mathrm{cm}^{-1}$, vibraciones de tensión del grupo C-O y C-O-C a 1111,62 $\mathrm{cm}^{-1}$ y un pico a $1059,65 \mathrm{~cm}^{-1}$ correspondiente a las vibraciones de tensión del grupo $\mathrm{C}-\mathrm{O}$. El espectro y las vibraciones de los grupos son similares a otras celulosas de origen bacteriano y vegetal encontradas en otros estudios, esto indicaría que la película producida por la cepa CBP-3,5 se trataría de un biopolímero de celulosa $\mathrm{a}^{20,24,25}$. 




Figura 3. Análisis químico mediante FT-IR de la película producida por la cepa BCP-3,5.

La metodología propuesta de Komagata et al. y Kersters et al. permite identificar las características fisiológicas y bioquímicas específicas del género Komagataeibacter, incluyendo a las especies capaces de producir celulosa ${ }^{16,17}$. Los resultados de las características fisiológicas y bioquímicas evaluadas para la identificación de la cepa CBP-3,5 se resumen en la tabla 1. Los resultados de la identificación mostraron que la cepa CBP-3,5 corresponde a la bacteria Komagataeibacter sp. Estos resultados son consistentes a los encontrados en otros estudios donde también utilizaron características fisiológicas para la identificación de esta especie bacteriana ${ }^{15,27}$.

Tabla 1. Resultados de la identificación de la cepa CBP-3,5.

\begin{tabular}{lcc}
\hline Características fisiológicas & Cepa CBP-3,5 & Komagataeibacter sp. ${ }^{16,17}$ \\
\hline Coloración Gram & Bacilos Gram & Bacilos Gram \\
negativos & negativos \\
Catalasa & + & + \\
Oxidación de etanol a ácido acético & + & + \\
Oxidación de ácido acético a $\mathrm{CO}_{2} \mathrm{y} \mathrm{H}_{2} \mathrm{O}$ & + & + \\
Oxidación de lactato a $\mathrm{CO}_{2}$ y $\mathrm{H}_{2} \mathrm{O}$ & + & + \\
Requerimiento de ácido acético para crecer & - & - \\
Crecimiento en $3 \%$ etanol (v/v) en presencia de 5 & - & - \\
$\%$ de ácido acético & - & + \\
Crecimiento en $30 \%$ de D-glucosa & + & + \\
Formación de ácido glucónico de D-glucosa & + & + \\
Producción de celulosa & & + \\
\hline
\end{tabular}




\section{CONCLUSIONES}

En este estudio se lograron aislar 7 cepas a partir de las 5 muestras de caña de azúcar, de estas cepas solo la cepa CBP-3,5 fue capaz de producir una película superficial en condiciones estáticas de incubación. La cepa BCP-3,5 fue identificada en base a sus características fisiológicas como Komagataeibacter sp. El análisis de FT-IR de la película producida por la cepa BCP 3,5 mostró que este biopolímero tiene un espectro similar a la celulosa de origen bacteriano y vegetal.

\section{AGRADECIMIENTOS}

Los autores agradecen de gran manera al Decano de la Facultad de Química e Ingeniería Química de la UNMSM y María Angélica Rodríguez Best, directora de la Unidad de Análisis Químicos (USAQ), por los servicios y facilidades otorgadas para la realización de este trabajo.

\section{REFERENCIAS}

1. Vandamme EJ, De Baets S, Vanaelen A, Joris K, De Wulf P. Improved production of bacterial cellulose and its application potential. Polym Degrad Stab. 1998;59(1-3):9399.

2. Lin S-P, Loira Calvar I, Catchmark JM, Liu J-R, Demirci A, Cheng K-C. Biosynthesis, production and applications of bacterial cellulose. Cellulose. 2013;20(5):2191-2219.

3. Campano C, Balea A, Blanco A, Negro C. Enhancement of the fermentation process and properties of bacterial cellulose: a review. Cellulose. 2016;23(1):57-91.

4. Yamada Y, Hosono R, Lisdyanti P, Widyastuti Y, Saono S, Uchimura T, et al. Identification of acetic acid bacteria isolated from Indonesian sources, especially of isolates classified in the genus Gluconobacter. J Gen Appl Microbiol. 1999;45(1):23-28.

5. Williams WS, Cannon RE. Alternative Environmental Roles for Cellulose Produced by Acetobacter xylinum. Appl Environ Microbiol. 1989;55(10):2448-2452.

6. Yamada Y, Yukphan P, Lan Vu HT, Muramatsu Y, Ochaikul D, Tanasupawat S, et al. Description of Komagataeibacter gen. nov., with proposals of new combinations (Acetobacteraceae). J Gen Appl Microbiol. 2012;58(5):397-404.

7. Wang J, Tavakoli J, Tang Y. Bacterial cellulose production, properties and applications with different culture methods - A review. Carbohydr Polym. 2019;219: 63-76.

8. Valla S, Kjosbakken J. Cellulose-negative mutants of Acetobacter xylinum. Microbiology. 1982;128(7):1401-1408.

9. Byrom D. Microbial cellulose. En: Byrom D, editor. Biomaterials: Novel Materials from Biological Sources. London: Palgrave Macmillan UK; 1991. p. 263-283.

10. Shoda M., Sugano Y. Recent advances in bacterial cellulose production. Biotechnol Bioprocess Eng. 2005;10(1):1-8. 
11. Pecoraro É, Manzani D, Messaddeq Y, Ribeiro SJL. Bacterial Cellulose from Glucanacetobacter xylinus: Preparation, Properties and Applications. En: Belgacem M, Gandini A, editors. Monomers, Polymers and Composites from Renewable Resources. Ámsterdam: Elsevier Science; 2007. p. 369-83.

12. Gorgieva S, Trček J. Bacterial cellulose: Production, modification and perspectives in biomedical applications. Nanomaterials (Basel). 2019;9(10):1352. doi: 10.3390/ nano9101352.

13. Hestrin S, Schramm M. Synthesis of cellulose by Acetobacter xylinum. II. Preparation of freeze-dried cells capable of polymerizing glucose to cellulose. Biochem J. $1954 ; 58(2): 345-52$.

14. Kurosumi A, Sasaki C, Yamashita Y, Nakamura Y. Utilization of various fruit juices as carbon source for production of bacterial cellulose by Acetobacter xylinum NBRC 13693. Carbohydr Polym. 2009;76(2):333-335.

15. Jahan F, Kumar V, Rawat G, Saxena RK. Production of microbial cellulose by a bacterium isolated from fruit. Appl Biochem Biotechnol. 2012;167(5):1157-71.

16. Kersters K, Lisdiyanti P, Komagata K, Swings J. The Family Acetobacteraceae: The Genera Acetobacter, Acidomonas, Asaia, Gluconacetobacter, Gluconobacter, and Kozakia. En: Dworkin M, Falkow S, Rosenberg E, Schleifer KH, Stackebrandt E, editors. The Prokaryotes: A Handbook on the Biology of Bacteria. New York, NY: Springer New York; 2006. p. 163-200.

17. Komagata K, Iino T, Yamada Y. The Family Acetobacteraceae. En: Rosenberg E, DeLong EF, Lory S, Stackebrandt E, Thompson F, editores. The Prokaryotes. Berlin, Heidelberg: Springer Berlin Heidelberg; 2014. p. 3-78.

18. Schramm M, Hestrin S. Factors affecting production of cellulose at the air/liquid interface of a culture of Acetobacter xylinum. J Gen Microbiol. 1954;11(1):123-9.

19. Wang Z-G, Xiang D, Wang X-B, Li C-F. Preparation of an inoculum of Gluconacetobacter xylinus without mutants in shaken culture. J Appl Microbiol. 2016;121(3):713-20.

20. Wang S-S, Han Y-H, Ye Y-X, Shi X-X, Xiang P, Chen D-L, et al. Physicochemical characterization of high-quality bacterial cellulose produced by Komagataeibacter sp. strain W1 and identification of the associated genes in bacterial cellulose production. RSC Adv. 2017;7(71):45145-55.

21. Yamanaka S, Sugiyama J. Structural modification of bacterial cellulose. Cellulose. 2000;7(3):213-25.

22. Tang W, Jia S, Jia Y, Yang H. The influence of fermentation conditions and post-treatment methods on porosity of bacterial cellulose membrane. World J Microbiol Biotechnol. 2010;26(1):125-131.

23. Laborie M-PG. Bacterial cellulose and its polymeric nanocomposites. En: Lucia LA, Rojas O, editors. The Nanoscience and Technology of Renewable Biomaterials. Chichester, UK: John Wiley \& Sons, Ltd; 2009. p. 231-271.

24. General considerations on structure and reactivity of cellulose: Section 2.3-2.3.7. En: Klemm D, Philipp B, Heinze T, Heinze H, Wagenknecht W, editores. Comprehensive Cellulose Chemistry. Weinheim, FRG: Wiley-VCH Verlag GmbH \& Co. KGaA; 2004. p. 83-129. 
25. Oh SY, Yoo DI, Shin Y, Seo G. FTIR analysis of cellulose treated with sodium hydroxide and carbon dioxide. Carbohydr Res. 2005;340(3):417-428.

26. Vasconcellos VM, Farinas CS. The effect of the drying process on the properties of bacterial cellulose films from Gluconacetobacter hansenii. Chem Eng Trans. 2018; 64: 145-150.

27. Zhang W, Wang X, Qi X, Ren L, Qiang T. Isolation and identification of a bacterial cellulose synthesizing strain from kombucha in different conditions: Gluconacetobacter xylinus ZHCJ618. Food Sci Biotechnol. 2018;27(3):705-713. 